\title{
Changes in Cattle Rustling on Gender Relations Among the Pokot in West Pokot, Kenya
}

\author{
Andrew Gitau Kimani ${ }^{1}$, Pacificah Kwamboka Okemwa ${ }^{1}$, Casper Masiga ${ }^{1}$
}

${ }^{1}$ Kenyatta University

P. 0. Box 43844-00100, Nairobi, Kenya

DOI: $10.22178 /$ pos.70-13

JEL Classification: K40

Received 16.04.2021

Accepted 28.05.2021

Published online 31.05.2021

Corresponding Author:

Andrew Gitau Kimani

drew.kimani@gmail.com

(C) 2020 The Authors. This article

is licensed under a Creative

Commons Attribution 4.0

License @ (1)

\begin{abstract}
Evidence of change in cattle rustling practice among pastoralist communities worldwide has been noted with globalisation, education, and modernisation, among other factors. However, there is little known about transformation in men and women's involvement in this practice in the wake of easy accessibility of small and light weapons and breakdown of the traditional leadership and control systems. This paper examined the transformation in cattle rustling practice among the Pokot community in West Pokot county. This study's target population included adult residents of the Pokot community, community elders, opinion leaders, political and administrative leaders, and local and international NGOs dealing with cattle rustling issues in West Pokot County. A multi-stage sampling technique was used to recruit 350 respondents. An unstructured questionnaire, a critical informant interview guide, a focus group discussion guide, and an observation guide were used to collect primary data. Qualitative data collected was analysed using patterns and critical themes of this particular objective. Quantitative data analysis was organised using the SPSS software version 2.0 and analysed using various descriptive statistics. The findings indicated that transformation in cattle rustling had seen a cultural activity for the young people to demonstrate their courage and wit and become a murderous criminal endeavour. The community no longer benefits from cattle rustling, but only a few are driven by greed to reap where they never sow. Illiteracy, poverty, unemployment, community conflicts, possession of firearms and insecurity were identified as the leading causes of cattle rustling. Access to formal education has seen many in the school-going age among the West Pokot get exposed to literacy, which has gradually recorded a positive transformation about its cattle rustling practices. Based on the findings, the paper makes the following recommendations to address the problem of cattle rustling among the people of West Pokot County: Enlightenment on contemporary ways of life; formal education among the Pokot to be advocated for; enhancing Security in West Pokot; opening a platform for peace talk and persuasions and operationalising the Eastern Africa Police Chiefs Cooperation Organisation protocol.
\end{abstract}

Keywords: Gender; Gender Relations; Cattle Rustling; Gender Transformation.

\section{INTRODUCTION}

Cattle rustling is a practice that is common in many communities globally. In many ways, it has altered gender roles and negatively impacts the family set-up, undermines development and disrupts the livelihoods of households. Studies show that families that have lost men (fathers or elder brothers) no longer had someone to provide for and protect them, while those that have lost women (mothers and/or sisters) have to do without caregivers their lives.
Pokot traditions enforce a well-respected hierarchy in the family where men (as husbands) are considered heads while women (as wives) are accorded authority and respect in chronological order. The first wife has the highest authority among the wives, which helps maintain social order. This implies that regarding cattle rustling, both men and women benefit from the proceeds of cattle raids by the relationship they share, mainly as husbands and wives. The proceeds of a cattle raid would then be used as a source of food and wealth for the family and benefit the man, his wives, and 
children [14]. However, individualism rather than communal ownership of land and wealth in the modern-day West Pokot means that there is a high likelihood that a woman will demand equal rights and control over family wealth as provided in the customary law of the Kenyan constitution [1].

As the practice of cattle rustling changes, the implications on gender relations to control and ownership of cattle are inevitable. It is noted that in patriarchal societies, the relations between men and women are unequal. Observably, in all societies, male domination and female subordination define such relations, thereby disadvantaging women. Scholars have noted that such subordination of women is a global phenomenon that is pegged on their universal roles and responsibilities as both mothers and homemakers. Gender roles and relations are diverse and are determined by contextual factors and change over time. Consequently, the need to interrogate issues affecting women and men due to the changes in gender roles deserve the attention of scholars.

Cattle rustling was historically perceived as a masculine oriented practice as it needed in its execution a degree of brutality, courage and perseverance, attributes that are associated with men in the practising communities. Traditionally, women were not allowed to carry out any cattle raiding. They were required to stay at homes, take care of the children and wait for their men who had gone out for raids. This is because women suffered more for, they are weak and needed protection, unlike the men who were able to run or fight [3].

Among the Pokot and other communities in which cattle raids are common, women play active roles in the practice. Observably, they transport and hide guns just like the men and depend on cattle rustling as a source of livelihood for their families, often resulting in some competition between the two genders [3]. This has been identified as a possible cause of breakdown in the family and a determinant of domestic violence in communities. It is worth noting that by the marital contract, men expect that women should look after them. However, when these men cannot perform society's roles, women may take them up, thus reversing the role plan in society. The men who cannot go for cattle raids to support their families are subjected to staying with their wife's family because they are not men enough to take care of their families. This has an emotional effect on men, who in turn lose self-esteem and respect in the community. In most cases, if a woman is married to a man who does not have enough cows and cannot raid, the woman has a right to leave him and go and marry someone else considered stable. This has changed marriage practices by giving women more power and freedom to choose a marriage partner who best suits their needs, yet this was not the practice [3].

Extreme conditions and changing spectrum in gender power relations have, over time, radicalised cattle rustling. Although there is plenty of literature on cattle rustling, previous scholars have hardly interrogated how gender roles have historically affected cattle rustling. Even with modernisation, both men and women have continually played interchangeable roles in the practice, given these roles are not static. The intensity, destruction and killing of women and children being witnessed in the wake of cattle rustling were unheard of traditionally because of the various taboos and customs that guided the practice [17].

Of interest, however, is the active involvement of both genders in cattle rustling. Observably, this has remained invisible, resulting in gender-blind approaches in tackling cattle rustling, which ultimately poses a severe security risk. This paper argues that the notable transformation in men and women's involvement in cattle rustling, compounded with a breakdown of traditional leadership and control systems; easy accessibility of small and light weapons (SALWs), pose a security threat that compromises meaningful efforts to curb the problem. The paper is hived from a doctoral thesis on a summary of a study that sought to interrogate gender transformation in cattle rustling and its implications on security management in West Pokot County.

\section{Theoretical framework}

To understand the complexity of cattle rustling, it is fitting to approach it from social cubism perspective. As a theory, social cubism has been utilised to identify challenges experienced in places where violence has erupted and assess the appropriateness of the interventions initiated to alleviate the problem. According to [2], Social Cubism Theory was predominately used in analysing territorial conflicts.

This approach is critical in understanding the cattle rustling related to conflict(s). As applied in this study, social cubism, as postulated by [2] seeks to 
explain conflict from historical, demographic, economic, psychological, religious, and political perspectives. According to [2], social cubism contains six interrelated aspects.

\section{Historical Aspect of Social Cubism. Authors [2]} argue that history is a robust frame of understanding almost everything about human existence. As one aspect of social cubism, understanding historical factors and/or events helps people understand some of the reasons behind intergroup dynamics and relationships. In essence, cattle rustling practise has roots in all pastoral communities because of livestock and their quick mobility and as a store of wealth and value. In most African societies, most ceremonies involved spilling blood, fat or/and milk to appease spirits and gods or general appreciation or blessings before a significant activity like a raid or praying for rain.

2. Religious Aspect of Social Cubism. Religion is one of the most polarising aspects known to humankind. For centuries, societies have fought, and millions of people have died because of religious differences. To social cubism, exploring religious dynamics helps people understand how religious beliefs affect intergroup relationships. Communities that were predominantly pastoralist were highly religious and involved the spirits of their forefathers and gods in everyday activities. In this respect, cattle raids were highly charged but a structured religious ceremony. It would involve, in most cases, burnt ceremonies being offered. A slaughtered goat, sheep, would have vital organs removed, and religious leaders' read' from them. Good omens could be interpreted from the patterns and singularities of the ligaments, among other signs in the heart, kidneys, intestines, among others. The neighbouring communities also had their diverse religious beliefs, occults and totems who defined good times and bad seasons, including predicting when a raid would be executed and why a raid targeted a community, especially when it had gone against their ways forbears, ancestors and gods.

3. Demographic Aspect of Social Cubism. Demographic factors are important aspects of exploring ethnic conflict. At the centre of demography is population compositions - especially about who is superior and inferior? Which ethnic group is more influential? Who controls wealth? Answering these questions allows people to understand how demographic issues affect the way ethnic groups view each other. Most pastoral communities have experienced high child mortality rates because of the ecological and environmental conditions surrounding them. Many children, especially boys, preferred to have enough defence against warring neighbours and a tremendous mobilising mechanism for raids, war, or other military excursions.

4. Political Aspect of Social Cubism. The political landscape in any given society affects how people and societies see each other. This is also true when it comes to understanding ethnic dynamics. In countries where a particular ethnic group dominates politics, there is always an ethnic suspicion by those who see themselves outside the political spectrum. In other words, countries where ethnic politics dominate political institutions run the risk of ethnic divisions that could eventually degenerate into inter-ethnic conflict if not dealt with properly. Most pastoral communities had a defined structure with elders' council, and decisions had to be filtered meticulously. Others had an anointed chieftain which influenced their approach to conflict and its resolution.

5. Economic Aspect of Social Cubism. Economic differences among ethnic groups significantly affect any society's political stability and security. It is known that economic disparity exacerbates tension among people, communities, and societies and even nations, particularly among political institutions that practice favouritism and/or ethnic patronage. In such countries, ethnic competition between different ethnic groups over who manages national resources usually affects peoples' perception of the government. In a nutshell, a country in which people from a particular ethnic group control economic institutions is likely to experience ethnic discontent or a sense of ethnic marginalisation. In contrast, a country in which economic institutions advocate for ethnic inclusion in all areas of its economy discourages ethnic discontentment. A large herd of livestock was a measure of the economic well-being of a community or individual. Loss of livestock through drought, natural attrition or theft and raid could precipitate conflict and worsen it.

6. Psychological Aspect of Social Cubism. Ethnic tension and emotions escalate during conflict or crisis. Regarding ethnic conflicts, psychologists often try to analyse how changes in people and/or societal behaviours and/or actions affect intergroup perceptions of others during tense moments. It is not surprising that political psychologists often find that groups or societies portray negative attitudes about each other. For example, 
promoting hate speech or bigotry, stereotypes, and prejudices highlights important ethnic traditions, symbols like ethnic identity, religious differences, heritages, and belief systems to inflame an ethnic or sectarian tension, resulting in an outburst of a physical or violent confrontation.

However, the authors [2] did not suggest that every conflict could be analysed using these six metrics of social cubism. Instead, they recognised the fact that different situations contain factors that relate differently. However, the use of this theory in the study conducted on the cattle rustling in West Pokot County ensured that conflict exploration was approached from different frames of analysis that exhibit traces of the six perspectives. The dynamics of gender in cattle rustling was therefore approached from these different directions and viewpoints. Gender serves as an underlying force whose transformation has shaped cattle rustling and its role in fostering conflict in the region.

With the transformation in gender roles that have taken place over time, the study found evidence of historical, psychosocial, political, religious, economic and demographic factors underlying the progression of cattle rustling. Therefore, the theory was instrumental in facilitating the interrogation of the various variables and themes of the study.

\section{Gender relations on cattle rustling}

A study by [14] revealed that traditionally men were charged with hunting, raiding/rustling animals, grazing cattle. At the same time, the women stayed home and took care of household responsibilities like building the huts, gardening (smallscale), preparing meals, and looking after the children.

However, as noted earlier, gender roles are not fixed, and they vary considerably over place and time. With the persistence of the cattle rustling, the men have been killed in raids, leaving many widows who have to fend for themselves and their children. The widows and other women have adopted new economic activities like brewing local beer, selling it, prostitution, and hawking. Men's roles have also changed over time due to the reduction in their cows and the restrictions to cross over to other territories to execute cattle raids. Consequently, they have started building houses and doing some gardening to supplement the relief food offered by the government.
Studies show that inability to carry out cattle raids may not change the identities of the men and women. However, there are few instances where gender roles have been transformed, thereby blurring masculinity and femininity identities among pastoralist communities. A case in point is alterations in men's roles as overall home providers in conflict and animal loss changes. Studies have shown that conflicts have rendered some to be dependent on women for virtually everything [16].

Authors [10] observed that women are most affected when sexual assault and exploitation are employed as tools of war. Moreover, women in conflict zones suffer from victimisation, alienation, prolonged emotional trauma and unwanted pregnancies. The author further notes that many communities had definite gender-segregated roles. Most of them discouraged their women from using weapons or engaging in any means of travel as they engaged in warfare. As culturally designated caregivers, women were expected to struggle to support their families and keep their households together even when conflict occurs. This is worsened by the fact that husbands and sons who are co-opted into wars cannot provide for their families in their absence.

Consequently, women are contemporarily shedding off the idea that only men can provide and protect communities and families. The changes are also a result of the introduction of machines that make work easy. Examples of these include vehicles that dissuade the need for walking long distances, thus lower tibial or leg endurance and weapons such as guns that do not require upper body strength like drawn bows, arrows, spears and machetes to utilise. The fact that SALWs require minimal strength in using has redefined the role of women. Cattle rustling has also become a lucrative commercial activity that has attracted women as 'middlemen' and financiers of the activities and as viable buyers of stolen stock. In a Western Australia Police Media release (March 20 2021), the police formed a special task force that identified a criminal enterprise and web that comprised of women and men and companies linked to the business of cattle theft, including aerial and ground musterers, livestock trucking companies, truck drivers, stock agents and feedlots.

\section{METHODOLOGY}

The study adopted a descriptive survey design. According to theory descriptive research design 
aims to collect detailed and factual information that describes an existing phenomenon. This research design also facilitated the use of a mixedmethods approach hence; questionnaire, an interview guide and an observation checklist were used to collect both quantitative and qualitative data for the study. The study sought to describe the gender relations on cattle rustling among the Pokot community in West Pokot County.

The target population included all adult men and women of 18 years and above in West Pokot County. The key informants included both women and men, community elders, opinion leaders, political and administrative officers, community members, and local and international NGOs. A total of 350 research participants were targeted, a sample size determined based on gender roles and biological sex, whether male or female.

The study employed both probabilistic and nonprobabilistic sampling techniques to identify study participants. Purposive sampling was used to identify National Government administrative units, including sub-counties, divisions, locations, and sub-locations based on reported incidences of cattle rustling. Cluster sampling was used to select villages. Within these, stratified random sampling was employed to ensure the representation of women and men in communities since gender was a critical variable that was investigated. The unit of analysis was the household. Therefore, based on the Kenya National Bureau of Statistics census of $2009,14 \%$ of the households were used for generalisation, and this was above the minimum $10 \%$ recommended for such a descriptive study.

Both quantitative and qualitative data were collected. Structured questionnaires containing both open and closed-ended questions were used in collecting data from women and men members of households. An interview guide was used to collect data from key informants who included the County Commissioner, the Deputy County Commissioners, the National Police Commanders, community leaders and representatives of both local and international NGOs operating in the study area.

Qualitative data were analysed using thematic analysis, while quantitative data were analysed using descriptive and inferential statistics. The study participants were not only assured of privacy, confidentiality and anonymity but were also voluntarily recruited to participate in the study. There was a written form for guaranteeing privacy, confidentiality and anonymity, where the respondents were to sign to confirm.

\section{RESULTS AND DISCUSSION}

This paper aims to assess the effects of changes in cattle rustling on gender relations among the Pokot in West Pokot, Kenya. The study examined various subthemes among them; the gender roles and raids, the role of women, involvement of unmarried young men and women; knowledge and responsibility for various stages of cattle rustling and how the practice of paying bride wealth is related to cattle raids.

\section{Gender roles and cattle rustling}

This section considers gender roles, responsibilities and cattle rustling among the Pokot of West Pokot, Kenya. Focusing on the gender roles in indigenous and contemporary cattle rustling reveals the progression of the practice over time and how these changes influence gender relations. Data from the study reveals that the responsibility of sanctioning, managing and utilising proceeds of raids varied significantly by gender both in the past and today, as in Figure 1.

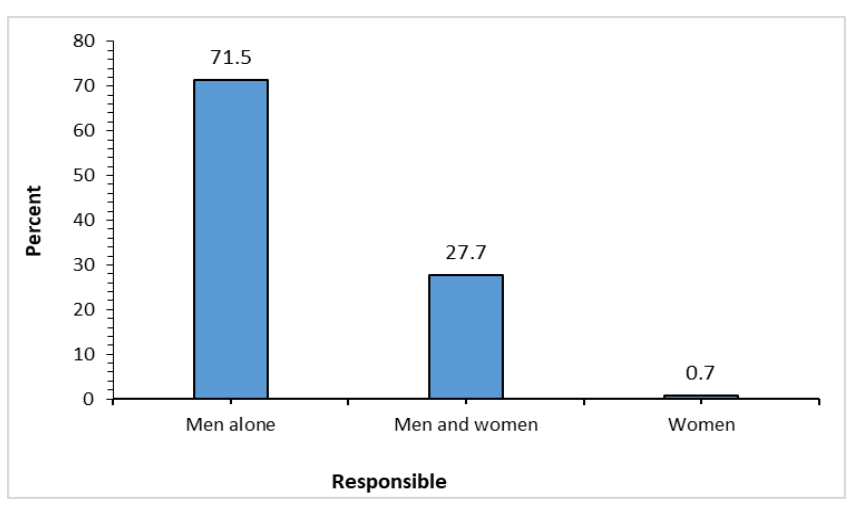

Figure 1 - Gender Roles and Cattle rustling

Men Alone. According to the study established that to a large extent, men (71.5\%) were solely responsible for planning, executing and managing livestock acquired from raids. Among the Pokot, a man is the head of the family and hence, entitled to the ownership or control of wealth in the family.

In furtherance, men were responsible for designing and making weapons, developing raid strategies, and carrying out raids. Men and women in the study also explained that since cows are a 
virtual currency and a sign of wealth and power in the region, livestock was essential to men. Thus Pokot men aspire to accumulate cattle which they use to pay the bride price (kandin) before marrying, among other uses.

Men and Women. Some $27.7 \%$ of the participants stated that men and women were jointly responsible for managing, controlling, and using proceeds of cattle raids. This means that cattle rustling was a joint mission in which men and women play significant roles. The findings affirm that each member of society plays a role in cattle raids to a certain degree. However, the extent of the involvement differs by gender, with men taking more active and visible roles while those of women are often passive and concealed.

Among the Pokot, a girl who had undergone circumcision was considered ready for marriage by a potential husband. He, however, had to have the capacity to pay a bride price. Consequently, young men would go to raids to acquire livestock to afford the bridewealth price, or they would risk being seen as outcasts according to the traditions of the Pokot. The bridewealth was paid to the girl's father, who then began arrangements to marry off his daughter. Consequently, both men and women benefited from the proceeds of cattle raids. The proceeds of a cattle raid would be used as a source of food and wealth for the family, which comprised the man, his wives, and children.

It is worth noting that individualism rather than communal ownership of land and wealth in the modern-day West Pokot means a high likelihood that a woman will demand equal rights and control over family wealth as provided in the customary law of the Kenyan constitution [1]. As cattle rustling changes, the implications on gender relations to control and ownership of cattle are inevitable.

Women. According to the study findings, only $0.7 \%$ of the men and women indicated that women were responsible for executing and managing the proceeds of a cattle raid. These findings correspond to the discussion by [15], who observed that traditionally, women were protected and not involved in the practice of cattle raids. For instance, the men and women in the FGDs unanimously agreed that women and children were not supposed to be hurt during cattle raids. Therefore, women's involvement in cattle raids was limited in the traditional Pokot culture and demonstrated in the views below:
During a cattle raid, women and children hide. It is the men that go out to fight and chase away raiders. Young Morans also protect the community at night when there are rumours that a raid is imminent (FGD Pokot North on 19.01.2019).

\section{Active Roles of Women in Cattle Rustling}

The study noted that women were key players in the sanctioning of a raid. Therefore, the various roles played by women were further probed by interrogating the data to illustrate this. In a singlegender FGD, it was noted that there are actions undertaken by women that instigate cattle raids. Given this, elder Kamket informed the study that:

Our women wear this Loketio (pregnancy support belt) as an honour to us. We use Loketio to prevent conflicts between communities/tribes. Loketio stops terrible acts. When a mother removes Loketio and just as the womb opens in childbirth, it is believed a woman who does this exposes her sons to the elements, which include curses or even death. When a mother passes on, beads or cowrie shells from her Loketio is sawn into the son's belt, hat or bangle. He will wear this at all time for his protection and safety. Women wear it to keep their families at peace. In cattle raids, when women are in support of the invasion, they wear Loketio. It reassures men that they are protected and will be successful in their raid (Kapenguria-Makutano, KII on 18.01.2019).

The findings align with [3], who points out that women were identified to initiate or escalate cattle raiding directly and indirectly. The author postulates this through actions like celebrating successful rustlers with a song while using mockery against those who did not participate in raids. Women, therefore, actively instigated raids through song and dance, a popular mode of communication among the Pokot. The women also highly regarded men with vast herds of cattle, while those without are seen as poor cowards who would not possibly take good care of a wife.

The study identified the various ways through which women were actively involved in modernday cattle rustling. These included praising warriors with song and dance, honouring brave warriors, supplying food and water to warriors in their hideouts, acting as spies, hiding raiders, nursing wounded warriors and going to raids. These roles are illustrated in Figure 2. 


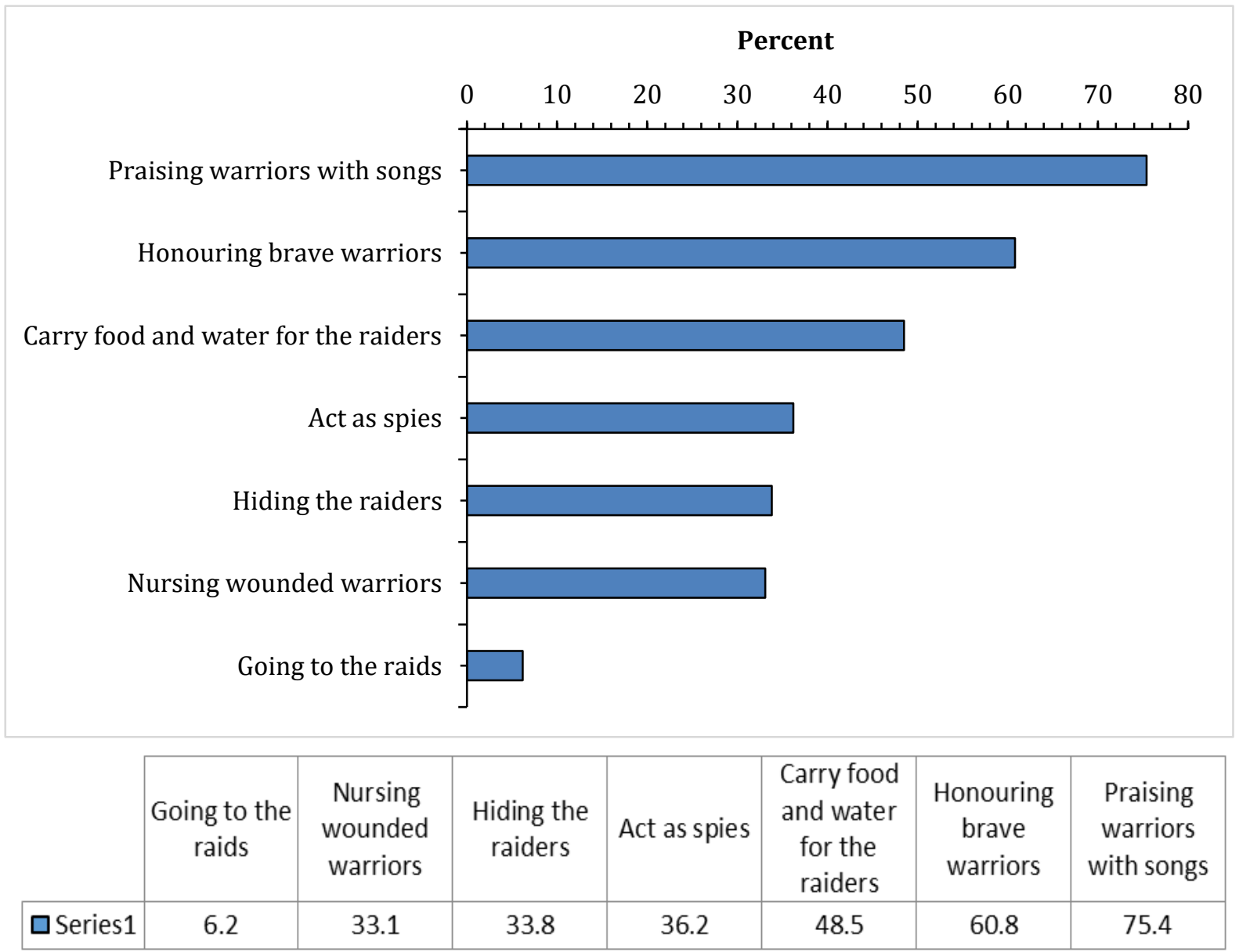

Figure 2 - The active role of Women in Cattle Rustling

Praising and honouring Warriors. Praising and honouring warriors was the most famous role played by Pokot women to cattle rustling. The study gathered that women used songs to encourage and congratulate men while going and returning from a raid. These findings cohere with the observations made by [15], who acknowledges that songs among the Pokot were powerful instruments for influencing behaviour. This is illustrated in the song below:
Pokot Translation

1-Leli pi Lokorio Lonapa a

2-Kamunyaita Chemalima

3-Nyo nyokiyaat lalwa na nya

4-Oh Kamina

5-Itepa Cherelkut a Kamina

6-Nyo kirya Lokotoro a kipel ko

7-Lokotepa wero Tulyany

8-Irwenye ngo oyu nya Kabelo?

9-Kipitei susweku koro Chepleng!
English

1-People are saying Lokorio Lonapa

2-Of Kammunyaita Chemalima

3-Who opened that river from the enemy

4-Oh Kamina

5-Ask the white mouthed beast

6-Who went to Lokotoro and burned a house

7-Lokotepa the son of Tulyany

8-You are sleeping up to when Mr Kabelo?

9-Your grass has already grown in Marakwet land!

Extracted in June 2015 from Audio Recording of Pokot Praise Songs by Paul Kipchumba.

This is a typical example of a song prompted by Pokot women in adong'o and joined by the young men in unison. It incites the Pokot cattle rustlers into planning for a raid against the Marakwet. Therefore, praise songs by Pokot women contribute a lot towards cattle rustling.
Supplying food and Water to Raiders. According to the study findings, a significant number of men and women, $48.5 \%$, stated that supplying food and water to raiders was the second most critical role that women played in the process of cattle 
rustling. The women facilitated the actions of the warriors by ensuring that they had supplies.

Elder Mangat reported that:

Women and children did not go out to raid. They supported cattle rustling by taking part in complementary roles such as giving them food and water. Warriors would be met with milk on return after a successful raid (Kapenguria-Makutano, KII on 18.01.2019).

Acting as Spies. The study findings revealed that young women and girls actively served as spies informing warriors about the plans and strategies of other communities. Information about the preparedness of the neighbouring communities was essential in ensuring that the warriors were not caught off guard. Women and girls travelling to fetch water would watch out for approaching raiders from higher grounds. While it was not a designated role for women and girls to spy on other communities, they had an obligation to relay any information on potential threats if they came across any.

In a KII an elderly lady, Lucy reported:

Women have a lot of information. I always knew when my husband was preparing to go on a raid. Sometimes I would overhear men discussing their strategies. I understood the proverbs, sayings and metaphors they used when discussing matters of war (Key informant interview in Pokot North on 15.01.2019).

An important aspect that facilitated women's roles as spies is the fact the Pokot marriages are exogamous. As a result, women are married outside their birth clans but cared deeply about the welfare of their kin. Thus, they would warn their tribesmen or women of an upcoming raid, especially when they met in the forest while gathering firewood or water pans. The information would be passed on to an eligible confidant, such as an older woman, who would then pass the message to the elders. The elders would then make decisions on how to defend the community or attack the aggressors.

These findings align with findings by [16], who established that women served as valuable informants for the warriors. Precisely, this meant that women, although not actively involved, we're keen to gather intelligence on the raids, which they passed on to warriors through well-established channels.
Hidings and Nursing Wounded Warriors. According to the study, women played an active role in hiding and nursing wounded warriors. As illustrated in Figure 2 above, a third of the men and women, $33.8 \%$ and $33.1 \%$ stated that women were actively engaged in hiding warriors from law enforcement agents and nursing wounded warriors, respectively. A key informant in the study reported:

Women alert their husbands to go and hide when there is an imminent operation. They take food to the hiding places (Chelangat, 21.01.2019).

Moreover, a key informant in the study reported that women still serve as informants for their husbands and sons whenever there is a disarmament operation. Jared, a KII reported:

Women and children transport guns from Kenya to Uganda when there is a mop-up or operation. They will also talk to the police and inform their husbands if there are signs of danger. Often, they can be heard saying, let me leave. I feel like there will be trouble here today (Key informant interview in Kibichbich on 17.01.2019).

The qualitative data gathered through the various key informant interviews indicates that women also helped the men transport guns. These findings are coherent with [8] observation that women are accomplices in propagating cattle rustling in Northern Kenya. In addition, the study observed that women and children in the community did not speak to strangers, making them good confidants for the men or warriors.

Going to Raids. The study established women's active involvement in raiding cattle was minimal, as indicated by $6.4 \%$ of the participants. In new cattle rustling, wealthy women are the masterminds and financiers under the guise of businesswomen, of rogue warriors (FGD Pokot North on 19.01.2019). Thus although women and children were majorly left out of the indigenous cattle rustling, some play an active role among the contemporary Pokot of West Pokot. These findings align with those by [3], who reports that in various pastoralist communities such as the Amazon, women were allowed to go on raiding sprees if they had the necessary skills and training.

\section{Roles of Young Unmarried Men and Women}

To further explore the impact of cattle rustling on gender relations, the study examined the traditional roles of young unmarried men and women 
in the Pokot community. As shown in Figure 3 below, young unmarried men and women had differing roles in cattle rustling. Women took precedence in specific roles while men had more significant responsibility in others. Some roles involved men alone, while in others, both men and women had a part to play.

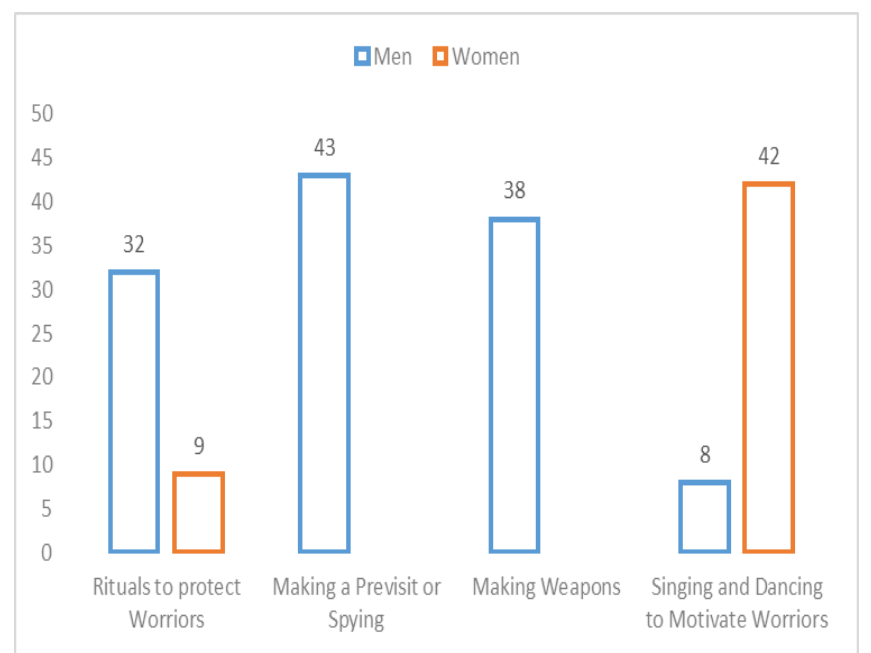

Figure 3 - Roles of Men and Women in Different Raid Stages

Performing Rituals to Protect Warriors. Figure 3 above shows that the majority $22.9 \%$ believed that men assumed a greater responsibility than women in performing rituals to protect warriors. On the other hand, only $6.4 \%$ of women were involved in performing rituals to protect warriors.

These findings were collaborated by insights gathered during FGDs in Kibichbich. In consensus, the FGD participants - both men and women explained:

Unmarried men and women do not perform rituals. Those are particular roles and can only be performed by older women or men (wilkoyong or laibon-pokot), especially past childbearing age. This is because a spiritual leader acquired the necessary skills for the trade upon many years of learning by doing, that is, by performing alongside the older ritual practitioners as they engaged in rituals aimed at cleansing warriors.

In Kibichbich, a KII reported that:

A spiritual leader had to observe certain precautions such as secrecy. Seers and prophets who blessed the warriors before they would leave for battle kept the secrets about planning and strategies of a cattle raid to their graves. Such responsibility could not be left to a young person. So, it takes many years for one to become a spiritual leader and to be able to perform rituals (Kapenguria-Makutano key informant interview on 18.01.2019).

These findings corroborate the observations by [15] that elders and spiritual leaders such as healers and seers conducted rituals before and after the raids underwent many years of training.

Making a Pre-visit or Spying. The study established that men were mainly responsible for making previsits and spying on neighbouring communities before a raid. The results shown in figure 3 above indicate that $30.7 \%$ of the men and women thought that young unmarried men were charged with conducting pre-visits and spying. According to [7], the treatment of young unmarried men and women varied within the community. This is because women were protected from harm, while young men were expected to protect their community even before circumcision. This explains why none of the men and women associated spying and conducting pre- visits to unmarried young women in the community. However, the study gathered from the FGD that older women spied and passed secrets to their clans as demonstrated in the qualitative data below:

A woman married off to the Turkana or Marakwet shares secrets with her clan about the plans and strategies. This helps her clan or community to prepare before a raid. However, young girls cannot travel long distances to go spy on the Turkana or Marakwet (FGD in Pokot North on 19.01.2019).

These findings agree with the views put across by [5], who stated that while women do not actively participate in cattle rustling, they often suffer the aftermath of the practice. For instance, in recent years, women and children mainly fall victim to the practice, with many having to pay the price with their lives.

Making Weapons. The study established that making weapons was solely a man's duty in the traditional Pokot culture. A majority of the men and women, $27.1 \%$ stated that young unmarried men in the traditional Pokot culture made most of the weapons used during cattle rustling. These findings are in line with [12] concluded that while women are involved, they conducted or executed the raids. Consequently, they developed craft and experience in practice, which included the development of weaponry. Jared, a KII reported that:

Young boys learnt the art of making arrows and bows from a young age. They would use them as play toys while grazing. Those that had special 
skills would graduate into making sophisticated weapons such as spears and swords (KII in Kibichbich on 17.01.2019).

Evidence from the focus group discussion indicated the life of s girl before marriage was steered in a different direction. The men and women unanimously agreed that:

A young girl was prepared for marriage since birth. The mothers taught their daughters the various roles of women, such as caring for children and the husband (FGD in Pokot North on 19.01.2019).

Ratemo, a KII, also supported the position. He reported that:

The Pokot did not value women. They force them into a marriage where a group of young men kidnapped a girl and took her to her husband's homestead without her consent. If a lady sees cattle being brought to her home, she knows it is not good and that her consent or denial thereof will not matter (Key informant interview at Kapenguria-Makutano on 19.09.2018).

In essence, making weapons was not aligned with a girl's destiny as a wife. Consequently, the girls were not allowed access to skills that were deemed manly. However, there is increased access to Small arms and light weapons in recent times, making cattle rustling more violent and radical. Women own guns and help men transport the guns, and this has encouraged women to participate in cattle rustling actively. In later years, [8] observed that the same justification was used to bar girls from attending school. Although many girls in Pokot attend school today, practices such as circumcision and early marriages still prevail in remote areas.

In summary, from the findings, it has been observed that there are changes affecting cattle rustling, mostly on gender relations among the Pokot. Although highly undervalued in the community, the study indicated that women had a significant role in steering cattle rustling.

\section{CONCLUSION}

The findings pointed out that as the practice of cattle rustling changes, the implications on gender relations to control and ownership of cattle are inevitable. Therefore, the limited coverage of the involvement of women-only reflects the high likelihood of being overlooked in developing strategies and interventions against cattle rustling. The study concluded that the gender interface directly affects cattle rustling because each one has a defined role, and a change affects the outcome and relations in practice. However, as noted, women's roles in cattle rustling are likely to be overlooked by security personnel to prevalent gender perceptions. Both men and women have had a role to play in the transformation. Men engaged in roles such as planning, making weapons and carrying out raids.

On the other hand, women participate mainly by influence, where they encouraged the men to pursue the practice and served complementary roles such as spying and secretly reporting. Elderly post-menopausal women with children who have married, similarly with men, could perform rituals to protect warriors. The gender interface directly affects cattle rustling because each one has a defined role, and a change in one affects the outcome and relations in practice.

This study examined the effects of gender relations on cattle rustling among the Pokot community in West Pokot County, Kenya. The findings provide scholarly literature on gender relations, gender transformation, security management in cattle rustling and their relationships in West Pokot County. This literature will help researchers and scholars because it will help them increase general knowledge on how the variables are related. This study has also provided empirical evidence that will be useful to policy practitioners to formulate policies and undertake the right actions to promote social and economic justices. The opening of multiple comprehensive peace forums that are friendly, participatory, and involving both genders should be explored. These forums should be permanent and cascaded to all levels of Administration and their views and solutions funded.

\section{REFERENCES}

1. Aldehaib, de A. (2013). Customary law and women's rights in a changing world. N. d.: LAP Lambert Academic Publishing.

2. Byrne, S., Carter, N., Senehi, J. (2002). Social Cubism and Social Conflict: Analysis and Resolution. ILSA Journal of International \& Comparative Law, 8(3), 725-740. 
3. Cheserek, G. J., Odenyo, V., \& Omondi, P. (2012). Nature and causes of cattle rustling among some pastoral communities in Kenya. Journal of Emerging Trends in Economics and Management Sciences, 3(2), 173-179.

4. Disney, J. L. (2008). Women's activism and feminist agency in Mozambique and Nicaragua. Philadelphia: Temple University Press.

5. Gitagno, J. (2015, March). Effects of alternative rite of passage on girls' education among the Keiyo community of Elgeyo Marakwet County, Kenya (Doctoral thesis), Egerton University

6. GOK, Kenya National Assembly. (2010, November 4). Report of the Select Committee

7. Greiner, C. (2013). Guns, land, and votes: Cattle rustling and the politics of boundary (re)making in Northern Kenya. African Affairs, 112(447), 216-237. doi: 10.1093/afraf/adt003

8. Guledani, K. (2011, February 8). Gender influence on educational process. Retrieved from http://www.gwi-boell.de/en/navigation/kreativwirtschaft-3079.html

9. Gumba, D., Alusala, N., \& Kimani, A. (2019, December). Vanishing herds. Cattle rustling in East Africa and the Horn. Retrieved from https://enact-africa.s3.amazonaws.com/site/uploads/2019-1218-vanishing-herds-research-paper-10.pdf

10. Kaimba, G. K., Njehia, B. K., \& Guliye, A. Y. (2011). Effects of cattle rustling and household characteristics on migration decisions and herd size amongst pastoralists in Baringo District, Kenya. Pastoralism: Research, Policy and Practice, 1(1), 18. doi: 10.1186/2041-7136-1-18

11. Kaprom, T. (2013). Effects of cattle rustling on economic development. A case of Masol Location, West Pokot County (Master's thesis), University of Nairobi. Nairobi.

12. Kenya Human Rights Commission. (2010). Moran no more. The changing face of cattle- rustling in Kenya. Retrieved from https://www.khrc.or.ke/mobile-publications/economic-rights-andsocial-protection-er-sp/54-moran-no-more-the-changing-face-of-cattle-rustling-inkenya/file.html

13. Kenya National Focal Point on Small Arms and Light Weapons. (2006). Kenya national action plan for arms control and management. Retrieved from https://www.files.ethz.ch/isn/124869/Kenya-National-Action-Plan-2006.pdf

14. Kimaiyo, D. (2016). Women involvement in cattle rustling between the Marakwet and the Pokot communities of North-Western Kenya (Doctoral thesis), University of Nairobi. Nairobi.

15. Lando, A. L., \& Kochomay, S. (n. d.). Traditional African Culture and Communication. Impact of Communication and the Media on Ethnic Conflict, 253-272. doi: 10.4018/978-1-4666-97287.ch015

16. MenEngage Alliance. (2017, 6-23 June). Policy Brief. Accelerating efforts to eliminate violence against women: Engaging men and boys in preventing and responding to violence against all women and girls. Retrieved from http://menengage.org/wpcontent/uploads/2017/06/MenEngage-Alliance-HRC35-brief-June-2017.pdf

17. Schilling, J., Opiyo, F. E., \& Scheffran, J. (2012). Raiding pastoral livelihoods: motives and effects of violent conflict in north-western Kenya. Pastoralism: Research, Policy and Practice, 2(1), 25. doi: $10.1186 / 2041-7136-2-25$ 